\title{
Aspectos Sócio-Econômicos das Pescarias Artesanais Realizadas no Complexo de Urubupungá e a Sua Jusante no Rio Paraná
}

\section{Socio-Economical Aspects of Artisanal Fisheries Carryed Out in the Urubupungá Complex and Down the Paraná River}

\section{CEREGATO, S. A. ${ }^{1}$ e PETRERE JR., M. $^{2}$}

\section{${ }^{1}$ Faculdades Claretianas - Av. 1, s/n - Rio Claro (SP). silvanac@claretian mpetrere@rc.unesp.br}

\section{RESUMO}

Para a execução deste trabalho foram considerados três ambientes: I) reservatórios de Ilha Solteira e Jupiá; II) rio Paraná entre as barragens de Jupiá e Porto Primavera; III) rio Paraná a jusante da barragem de Porto Primavera. O levantamento de dados foi feito mediante a aplicação de questionários, num total de 187 pescadores entrevistados, sendo que apenas 164 entrevistas foram consideradas válidas. As entrevistas foram feitas em julho/98 (época seca) e fevereiro/99 (época chuvosa). O objetivo deste trabalho foi o de relacionar as várias variáveis ou fatores ligados diretamente à atividade pesqueira (ambiente em que o pescador atua, época da entrevista (seca ou chuvosa), aparelhos utilizados na pesca, número de dias em que pesca durante a semana, material utilizado na embarcação e sistema de impulsão empregado pelo pescador), bem como de algumas variáveis sócio-econômicas (idade, estado civil, número de dependentes, instrução e busca de outra atividade no período da entressafra da pesca). Através de medidas descritivas e testes estatísticos pode-se concluir que cerca de $75 \%$ dos pescadores entrevistados têm até 50 anos e são casados. Cerca de $64 \%$ dos pescadores têm até três dependentes e há predomínio do curso primário ou $1^{\circ}$ grau (completo ou incompleto) entre os entrevistados. Estatisticamente, a busca por outra atividade remunerada no período da entressafra da pesca, o material utilizado na embarcação e o número de dias que pesca durante a semana dependem do ambiente e da época em que o pescador está exercendo sua atividade. Os aparelhos mais freqüentemente empregados são as redes de espera, que predominam nos ambientes 1 e 2, 
e espinhel, mais freqüente no ambiente 3 .

PALAVRAS-CHAVE: Pesca interior, represas, rios, aspectos sócio-econômicos.

\section{ABSTRACT}

To accomplish this study three habitats had been considered: I) Ilha Solteira and Jupiá reservoirs; II) Paraná river between the dams of Jupiá and Porto Primavera; III) Paraná river down the Porto Primavera dam. The data collection was carried out by the application of questionnaires to a total of 187 fishermen, of those just 164 interviews had been considered valid. They were applied on July 1998 (dry season) and February 1999 (rainy season). The objective of this paper was to make a list of the variables directly linked to the fishing activity (such as habitats, seasons - dry or rainy, gears used in the fishing, days of fishing during the week, material used in the boat and motorized (or not) boat) as well as some socio-economical variables (age, civil status, number of dependents, education, search of another activity during the decline of fisheries).Through descriptive measures and statistical tests, it was concluded that nearly $75 \%$ of the fishermen are less than 50 years old and they are married. Nearly $64 \%$ of interviews have up to 3 dependents and there is a predominance of primary school (complet or incomplet). Statistically, the search for another activity in the decline of fishing in the season, the material used in the boat and the number of days of fishing during the week depend on habitats and season where fishermen are acting. The gears more frequently used are gillnets, that prevail in the habitats 1 and 2, and longline, more frequent in the habitat 3.

KEYWORDS: inland fisheries, dams, rivers, socio-economical aspects

\section{INTRODUÇÃO}

Os rios têm exercido papel importante no povoamento em diversas regiões do mundo, pois a água é um dos elementos essenciais à vida. Por serem um recurso fundamental para o funcionamento da sociedade e do ambiente, as águas doces sofrem constantes mudanças em sua distribuição, abundância e qualidade. Essas pressões sobre o ecossistema aquático se refletem na integridade do próprio meio, bem como nas culturas humanas (NAIMAN \& TURNER, 2000).

Seja como fonte de água e alimento, seja como meio de transporte ou auxiliando na orientação para penetração em territórios desconhecidos, os rios fazem parte da História, desde as antigas civilizações (PAIVA, 1982). No Brasil, o quadro não é diferente. Na Amazônia, por exemplo, a grande quantidade de água e fartura de pescado contribuíram para a ocupação da região: as populações humanas buscavam as margens 
dos rios e lugares piscosos para se fixarem (LEONEL, 1998). Atualmente, a relação de dependência entre homem e rio tem se estreitado. $\mathrm{O}$ controle da água determina o ritmo do progresso, pois, além de serem utilizados para abastecimento, irrigação, fonte de alimento e navegação, também são utilizados para a produção de energia elétrica, recreação e lazer.

A construção de barragens e reservatórios é, desde há muito tempo, uma alternativa para o abastecimento de água e irrigação, além de proteger áreas contra inundação e servir a aqüicultura. Porém, tais obras alteram os ecossistemas naturais (PETRERE, 1996).

Em alguns casos, os efeitos das barragens podem ser positivos, como é o caso do rio Tietê, em São Paulo. Nele, as seis barragens construídas e administradas pela CESP - Companhia Energética de São Paulo**, funcionam como verdadeiras lagoas de decantação, contribuindo para a melhoria de qualidade da água poluída que é lançada no seu leito (PETRERE, 1990).

$\mathrm{Na}$ Amazônia, entretanto, a construção da represa de Tucuruí (área inundada de $2.430 \mathrm{Km}^{2}$, potência de $3.980 \mathrm{MW}$, perfazendo $1,64 \mathrm{MW} / \mathrm{Km}^{2}$ ) tem apresentado uma série de impactos indesejáveis como a proliferação de mosquitos, que já existiam na região mas que tiveram um aumento acentuado, prejudicando a população que vive na periferia do reservatório. Além disso, houve uma alteração na ictiofauna a sua montante, observada através do aumento de curimatã Prochilodus nigricans e do declínio generalizado de grandes bagres migradores (PETRERE, 1990).

Porém, nada se compara ao desastre ecológico irreversível que ocorreu com a construção da hidrelétrica de Balbina, também na Amazônia, que inundou uma área de $2.346 \mathrm{Km}^{2}$, alterando todo o ecossistema da região e cuja potência nominal é de apenas $250 \mathrm{MW}$, ou seja, $0,11 \mathrm{MW} / \mathrm{Km}^{2}$, enquanto que a usina hidrelétrica de Itaipu, por exemplo, gera 8,63 MW/Km² (PETRERE, 1990).

Atualmente, cerca de $63 \%$ do potencial de energia hidráulica brasileira está sendo utilizado. A maior parte do potencial não utilizado situa-se na Amazônia o que implica em consideráveis impactos ambientais, caso tais recursos sejam utilizados (ROSA et al., 1995). A utilização dos ambientes aquáticos para diferentes atividades geram, muitas vezes, conflitos pois podem alterar sua dinâmica (BARRELLA et al., 2000). É preciso que a utilização dos recursos hídricos seja mais eficiente, de modo que se tenha como prioridade a conservação da água, ainda mais quando se vislumbra para as próximas décadas um déficit deste recurso natural.

Nem sempre aquilo que o ecossistema oferece como bem ou serviço é comercializável, ou tem preço direto, como, por exemplo, o fitoplâncton de uma represa. 
Muitas vezes o valor é intrínseco pois, direta ou indiretamente, serve de alimento para os peixes, estes sim comercializáveis. Assim, WILSON \& CARPENTER (1999), numa revisão sobre a valoração econômica dos serviços de água doce nos EUA, de 1971 a 1997, chamaram a atenção para esse fato e discutem metodologias para valorar esse tipo de serviço. Porém, o conceito de valor depende das circunstâncias sob as quais é atribuído, pois as escolhas econômicas são feitas sempre comparativamente e as decisões tomadas por um grupo de pessoas podem prejudicar outras, principalmente na pesca que explora um recurso de acesso aberto, o estoque pesqueiro (HARDIN, 1968; SIMPSON, 1998).

Apesar da pluralidade de suposições e metodologias para a valoração de bens e serviços fornecidos pelo ecossistema, principalmente os recursos hídricos, as limitações e incertezas são comuns. Para minimizá-las, faz-se necessário estudos interdisciplinares para quantificar os recursos do ecossistema, determinar as relações dessas quantificações com variáveis limnológicas, além de relacionar tais informações com os aspectos sociais e culturais, facilitando os caminhos para futuros projetos de manejo de recursos (WILSON \& CARPENTER, 1999).

A rede hidrográfica brasileira é uma das mais homogêneas e densas do mundo. O território brasileiro encontra-se dividido em 9 grandes bacias hidrográficas. Com o crescimento populacional do país, o desenvolvimento de novas áreas agrícolas e também devido à construção de represas geradoras de energia, essas bacias têm sido amplamente exploradas (PAIVA, 1982).

O rio Paraná (que significa "pai das águas", na língua guarani) e seus tributários formam uma das maiores bacias hidrográficas da América do Sul, com área de 2.800.000 $\mathrm{Km}^{2}$, incluindo a maior parte das regiões Sudeste e Sul do Brasil, Paraguai, porção oriental da Bolívia e nordeste da Argentina (ENCICLOPEDIA BRITANNICA, 1981). Existem cerca de 600 espécies de peixes em toda a bacia Paraná-Paraguai (BONETTO, 1986). Através de pescas experimentais ao longo do rio Paraná e em seus reservatórios, foram relacionadas, na porção brasileira, 311 espécies de peixes agrupadas em 36 famílias. A família Characidae se mostra mais representativa, com 83 espécies, seguida pelas famílias Pimelodidae e Loricariidae, com 40 e 35 espécies, respectivamente (PETRERE et al., 1998).

Algumas espécies de peixes foram introduzidas na bacia do Paraná, como a curvina Plagioscion squamosissimus, o tucunaré Cichla monoculus, o trairão Hoplias lacerdae e o apaiari Astronotus ocellatus, provenientes da bacia Amazônica, a carpa Cyprinus carpio, proveniente da Ásia e a tilápia Oreochromis niloticus, oriunda da África (AGOSTINHO et al., 1994(a)). Destas, a curvina Plagioscion squamosissimus é a espécie que se adaptou com maior facilidade (PETRERE \& AGOSTINHO, 1993).

Até o início da década de 50, quando a maioria das pescarias era feita no 
leito dos rios, espécies como o pintado Pseudoplatystoma corruscans, o dourado Salminus maxillosus e o jaú Paulicea luetkeni tinham grande representatividade nas capturas. Atualmente, as pescarias, em sua maior parte, são efetuadas nas represas, com captura de espécies de menor valor comercial, como a sardela ou mapará Hypophthalmus edentatus, o armado Pterodoras granulosus, etc. (PETRERE, 1995).

Com o objetivo de suprir as deficiências energéticas do país, o planejamento do aproveitamento dos rios deixa de lado os outros usos fundamentais tais como: navegação, controle das cheias, irrigação, abastecimento, diluição de efluentes, habitat des animais, pescarias ou simplesmente o lazer da população (LEONEL, 1998).

A construção de represas diminui a riqueza da ictiofauna nos rios. Na bacia do rio Paraná, este fato se mostra evidente, pois as represas interferem, principalmente, no processo reprodutivo das espécies migradoras, como o pintado Pseudoplatystoma corruscans, o dourado Salminus maxillosus e o jaú Paulicea luetkeni, que são importantes na pesca comercial (AGOSTINHO et al., 1994(a)).

Além do impacto causado pelas represas, a poluição é outro fator que afeta a ictiofauna e, conseqüentemente, as pescarias. Proveniente de efluentes urbanos e industriais, da agricultura intensiva e do desmatamento da mata de galeria, a poluição provoca sérios impactos nos rios e também nos reservatórios (PETRERE, 1989).

Nos reservatórios existentes na bacia do Paraná, a produtividade da pesca é baixa (PETRERE \& AGOSTINHO, 1993; PETRERE, 1996). Um estudo comparando o rendimento e a produção indicou que a produção média em sete reservatórios da bacia do Paraná é de 4,51 kg/ha/ano (PETRERE \& AGOSTINHO, 1993), muito baixa se comparada aos valores médios de lagos e reservatórios africanos, que são de 58,4 $\mathrm{kg} / \mathrm{ha} /$ ano (BAYLEY, 1988) e 99,5 kg/ha/ano (MARSHALL, 1984), respectivamente, e mesmo do Nordeste brasileiro, cujo valor médio para 17 açudes é de 151,8 kg/ha/ano (PAIVA et al., 1994).

A despeito da baixa produtividade nos reservatórios, e mesmo nos rios, em algumas regiões brasileiras a pesca é a única fonte de proteína e de renda para as populações ribeirinhas. Além disso, a pesca artesanal gera emprego direto a 200 mil pescadores, e uma série de empregos indiretos através da comercialização do pescado (CHAGAS, 1994). Porém, ainda não há uma política pública adequada que atenda à tais necessidades. O quadro apresenta-se caótico no que diz respeito à infra-estrutura de desembarque, tecnologias de pesca, conservação e comercialização do pescado, além dos conflitos sociais que envolvem os pescadores artesanais (LEONEL, 1998).

Pesquisas e estudos para gestão e manejo dos recursos são necessários para melhor aproveitamento dos estoques pesqueiros. No reservatório de Itaipu, por exemplo, o NUPELIA - Núcleo de Pesquisas em Limnologia, Ictiofauna e Aquicultura, 
Universidade Estadual de Maringá - PR, acompanha, desde janeiro de 1987, os desembarques diários de pescado. Através desse estudo é possível analisar os fatores que intervêm na captura, enfatizando as limitações e potenciais do seu desenvolvimento no ambiente alterado pela construção do reservatório (AGOSTINHO et al., 1994(b)).

Por ser atividade econômica tão importante para grande parte da população brasileira haveria a necessidade de uma boa avaliação e monitoramento dos estoques pesqueiros, objetivando a manutenção e, se possível, o aumento da produção pesqueira (TORLONI et al., 1993).

O Estado de São Paulo possui um número considerável de usinas hidrelétricas. Os impactos causados por suas barragens, principalmente na ictiofauna, fazem com que a atividade pesqueira sofra alterações ao longo do tempo e, conseqüentemente, a sua rentabilidade se altere.

O objetivo geral deste trabalho foi o levantamento do perfil sócio-econômico dos pescadores, dos aparelhos e equipamentos utilizados na pesca e identificar das espécies mais capturadas nos diferentes ambientes.

\section{MATERIAL E MÉTODOS}

A área de estudo desta pesquisa é a sub-região da bacia do Rio Paraná, que inclui os reservatórios do Complexo de Urubupungá, formado pelas Usinas Hidrelétricas de Jupiá e Ilha Solteira, e o leito do Rio Paraná a sua jusante. Considerando as possíveis diferenças existentes na área de estudo como um todo, a mesma foi subdividida em três ambientes:

- Ambiente 1: reservatórios do Complexo Francisco Lima de Souza Dias (ou Complexo de Urubupungá), que inclui as Usinas Hidrelétricas Engenheiro Souza Dias (Jupiá) e Ilha Solteira;

- Ambiente 2: trecho do rio Paraná, entre o Complexo de Urubupungá e a barragem da Usina Hidrelétrica Engenheiro Sérgio Motta (Porto Primavera);

- Ambiente 3: trecho do rio Paraná imediatamente a jusante da barragem de Porto Primavera.

Os pontos de coleta considerados neste trabalho foram os núcleos de pescadores de localidades pertencentes à área de estudo, ou seja:

- Ilha Solteira, Itapura e Rubinéia, no Estado de São Paulo, que atuam nos reservatórios de Jupiá e Ilha Solteira; 
- Três Lagoas, no Estado de Mato Grosso do Sul, Presidente Epitácio e Panorama, no Estado de São Paulo, que atuam no trecho do rio Paraná, entre as barragens de Jupiá e Porto Primavera;

- Porto Rico, no Estado do Paraná e Porto Primavera, no Estado de São Paulo, que atuam no leito do rio Paraná, a jusante da barragem de Porto Primavera.

A coleta de dados foi realizada através de entrevistas com os pescadores que atuam nos núcleos de pesca pertencentes à área de estudo.

O procedimento para realizar as entrevistas foi o chamado "bola de neve": ao chegar na localidade, buscava-se a colônia de pescadores ou locais onde se encontraria algum pescador. Tendo entrevistado o primeiro, obtinha-se a informação de onde encontrar o próximo, e assim sucessivamente.

Através do número estimado de pescadores que atuam no local, informado pelo próprio pescador em sua entrevista, obteve-se um número médio estimado de pescadores e, assim, procurou-se entrevistar, ao menos, $10 \%$ dessa população.

As coletas de dados ocorreram em dois períodos: o primeiro, em julho/98 (época seca) e o segundo, em fevereiro/99 (época chuvosa). No caso de um mesmo pescador ser entrevistado nas duas épocas, optou-se por sortear seu questionário, a fim de evitar duplicidade de informações e para preservar a independência entre as épocas, no momento das análises estatísticas dos dados. O questionário considerado (ANEXO I) foi construído a partir de vários modelos existentes na Literatura, como o utilizado por CAMARGO (1998), MENDONÇA (2000), OKADA et al. (1997) e SANTOS et al. (1995).

Através de entrevistas foi possível fazer o levantamento dos aspectos econômicos e sociais dos pescadores como idade, estado civil, escolaridade, tempo que desempenha a atividade pesqueira no ambiente considerado, etc; determinar os aspectos diretamente ligados à pesca como: material da embarcação, tipo de impulsão, tipos de aparelhos (tarrafas, redes de espera, vara/molinete, espinhel, etc.) e dias que pesca durante a semana; relacionar as espécies mais capturadas, nos diferentes ambientes.

As variáveis sócio-econômicas como idade, estado civil, escolaridade e número de dependentes, foram analisadas, descritivamente, através de tabelas de distribuição de freqüências (DANIEL, 1995).

Tabelas de contingência, resumindo informações das variáveis "tipo de embarcação" e "presençalausência de motor", consideradas em função do ambiente, foram analisadas através de um teste de independência, utilizando a estatística $\chi^{2}$ (tabelas bi-dimensionais). Já a variável "atividade na entressafra da pesca", considerada por ambientes e épocas de coleta, foi resumida e analisada através de tabela de contingência 
multi-dimensional (EVERITT, 1977). O número de dias em que o pescador exerce sua atividade durante a semana foi investigado em função do ambiente e da época de coleta dos dados. A teoria de modelos log-lineares foi empregada (EVERITT, 1977; AGRESTI, 1984) para testar a independência dessas variáveis.

\section{RESULTADOS E DISCUSSÃO}

A primeira coleta de dados foi realizada no período de 10 a 21 de julho de 1998, considerado um período de seca. Foram visitadas 12 localidades e preenchidos 82 questionários. Durante a segunda coleta, realizada no período de 18 a 28 de fevereiro de 1999, considerada uma a época chuvosa, foram visitadas 9 localidades e preenchidos 105 questionários. Porém, o número de questionários considerados válidos é de 164 pois alguns pescadores foram entrevistados nas duas épocas.

Devido às grandes dimensões da área considerada neste estudo, não foi possível determinar o número de pescadores profissionais que atuam no leito do rio Paraná e nas represas de Jupiá e Ilha Solteira. O número estimado de pescadores para águas continentais do Estado de São Paulo é de 2.833 indivíduos (SANTOS et al., 1995). Destes, estima-se que 642 atuam no rio Paraná e nas represas do Complexo de Urubupungá. Em visita a 25 municípios, durante os anos de 1992 e 1993, a equipe do Instituto de Pesca Paulista cadastrou 261 pescadores. Se esses números não sofreram grandes modificações, os 164 pescadores entrevistados nesse trabalho representam cerca de 5,6\% do total de pescadores estimado para o Estado de São Paulo, e 25,5\% do número estimado de pescadores que atuam em área equivalente à considerada nesta pesquisa.

A idade média dos pescadores, nos três ambientes considerados, não apresenta grande diferença, como pode ser observado na Figura 1. A pesca é uma atividade que não estabelece limites de idade a seus praticantes: durante a $2^{\mathrm{a}}$ coleta, foi entrevistado o pescador mais novo (19 anos), e mais velho (80 anos), nos ambientes 2 e 3 , respectivamente. A freqüência de pescadores com idade avançada é menor nos três ambientes estudados. A maioria dos pescadores (74,4\%) tem até 50 anos. Acima dos 60 anos, observaram-se apenas 7,9\% dos entrevistados. No reservatório de Itaipu, a distribuição dos pescadores em relação às faixas etárias apresenta-se de forma semelhante, pois cerca de 79\% dos pescadores têm até 50 anos (AGOSTINHO et al., 1994(b)). Ao longo do rio São Francisco, a idade média dos pescadores é de 44,4 anos, com valores mínimo e máximo de 20 e 72 anos, respectivamente (CAMARGO, 1998). Estudos realizados por OKADA et al. (1997), mostraram que a idade média dos pescadores do reservatório de Segredo é de 37 anos, tendo grande concentração nas faixas etárias até 50 anos (cerca de 75\% dos indivíduos). 


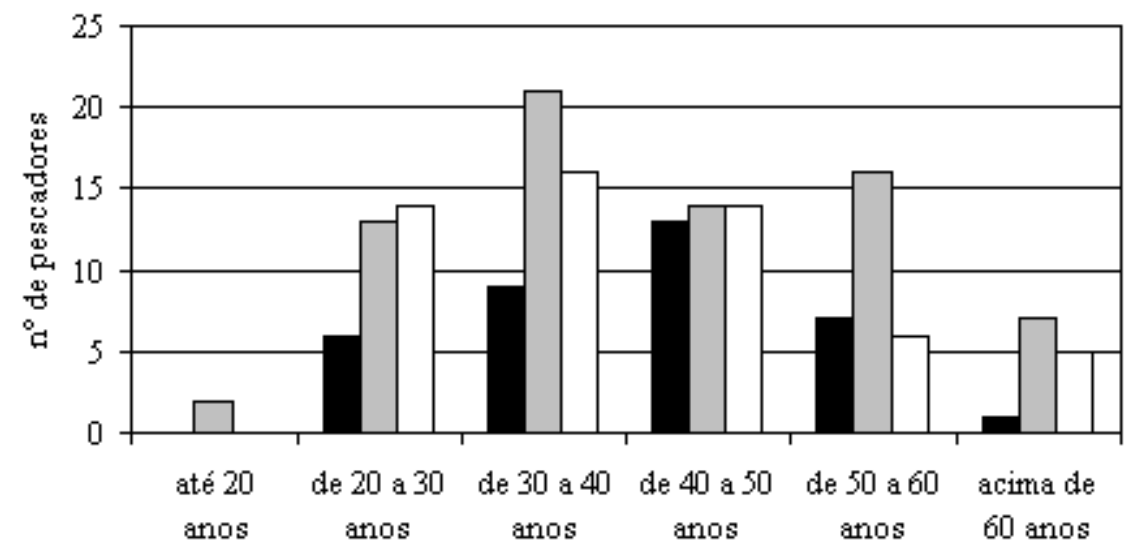

Ambiente $1 \square$ Ambiente $2 \square$ Ambiente 3

Figura 1. Freqüências dos pescadores em relação à idade, nos três ambientes considerados. Ambiente 1: reservatórios de Ilha Solteira e Jupiá; Ambiente 2: trecho do rio Paraná entre as barragens de Jupiá e Porto Primavera; Ambiente 3: trecho do rio Paraná a jusante da barragem de Porto Primavera.

Questionados em relação ao incentivo que dão para que os filhos continuem atuando na profissão exercida pelos pais, vários pescadores disseram desejar "outra vida" para os filhos. Tal fato pode ser observado na pouca freqüência de pescadores jovens (abaixo de 20 anos). Alguns filhos (dependentes) de pescadores atuam como ajudante de pesca para seus pais porém não têm expectativas de que essa atividade torne-se sua fonte de renda futuramente.

A grande maioria dos pescadores (78,0\% dos entrevistados) é casada. Dentre os entrevistados, $16,5 \%$ são solteiros, $4,3 \%$ são separados/divorciados e apenas $1,2 \%$ são viúvos.

Levando-se em consideração o fato de que a maioria dos pescadores é chefe de família, foi feito levantamento acerca do número de dependentes por pescador (Figura 2). 


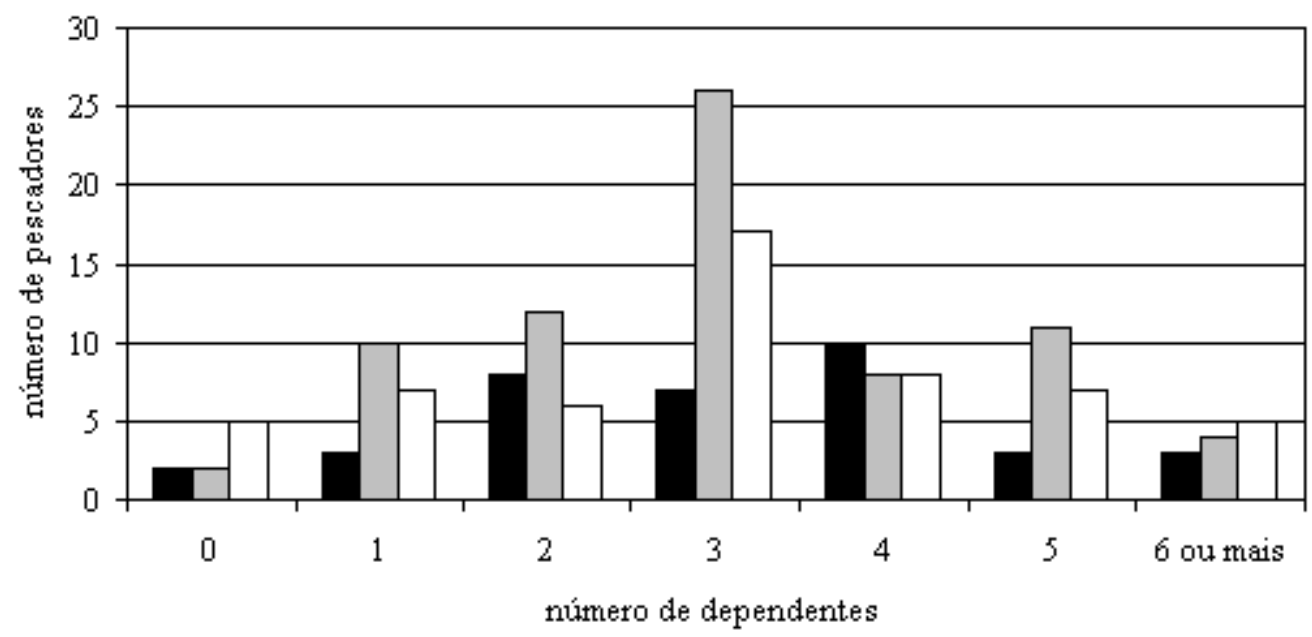

Ambiente $1 \square$ Ambiente $2 \square$ Ambiente 3

Figura 2. Distribuição de freqüências segundo o número de dependentes por pescador, nos três ambientes considerados. Ambiente 1: reservatórios de Ilha Solteira e Jupiá; Ambiente 2: trecho do rio Paraná entre as barragens de Jupiá e Porto Primavera; Ambiente 3: trecho do rio Paraná a jusante da barragem de Porto Primavera.

$\mathrm{O}$ número de dependentes por pescador atingiu o máximo de nove indivíduos, sendo que $64,1 \%$ dos entrevistados têm até três dependentes. Apenas 3\% dos entrevistados alegaram possuir sete dependentes ou mais, sendo que este valor, em 92/93, para os pescadores de águas continentais do Estado de São Paulo, era de 7,2\% (SANTOS et al., 1995).

Durante a $1^{\text {a }}$ coleta, constatou-se que, em média, os pescadores dos ambientes 1,2 e 3 têm 3,6, 3,2 e 3,0 dependentes, respectivamente. Na $2^{\text {a }}$ coleta, esse número médio diminuiu para 2,9 dependentes por pescador, para os ambientes 1 e 2 , enquanto que no ambiente 3, aumentou para 3,1 dependentes por pescador. Comparando com dados do IBGE a respeito do número médio de componentes da família, verifica-se uma ligeira superioridade numérica desses valores, pois para o Estado de São Paulo, por exemplo, o número médio de indivíduos por família é de 3,64 pessoas. No reservatório de Itaipu, estimaram-se 3,1 dependentes por pescador (AGOSTINHO et al., 1994(b)) e entre os pescadores do rio São Francisco esse número médio foi estimado em 5,2 dependentes por pescador (CAMARGO, 1998).

Com esses resultados, observa-se que as famílias não são tão numerosas e, apesar da pesca ser atualmente uma atividade pouco lucrativa, os chefes de família continuam sustentando seus dependentes com a pesca e, quando necessário, buscam complemento de renda em outras atividades não ligadas à pesca, principalmente no período ruim de pesca. 
Na Figura 3, são apresentados os diversos graus de escolaridade dos pescadores entrevistados.

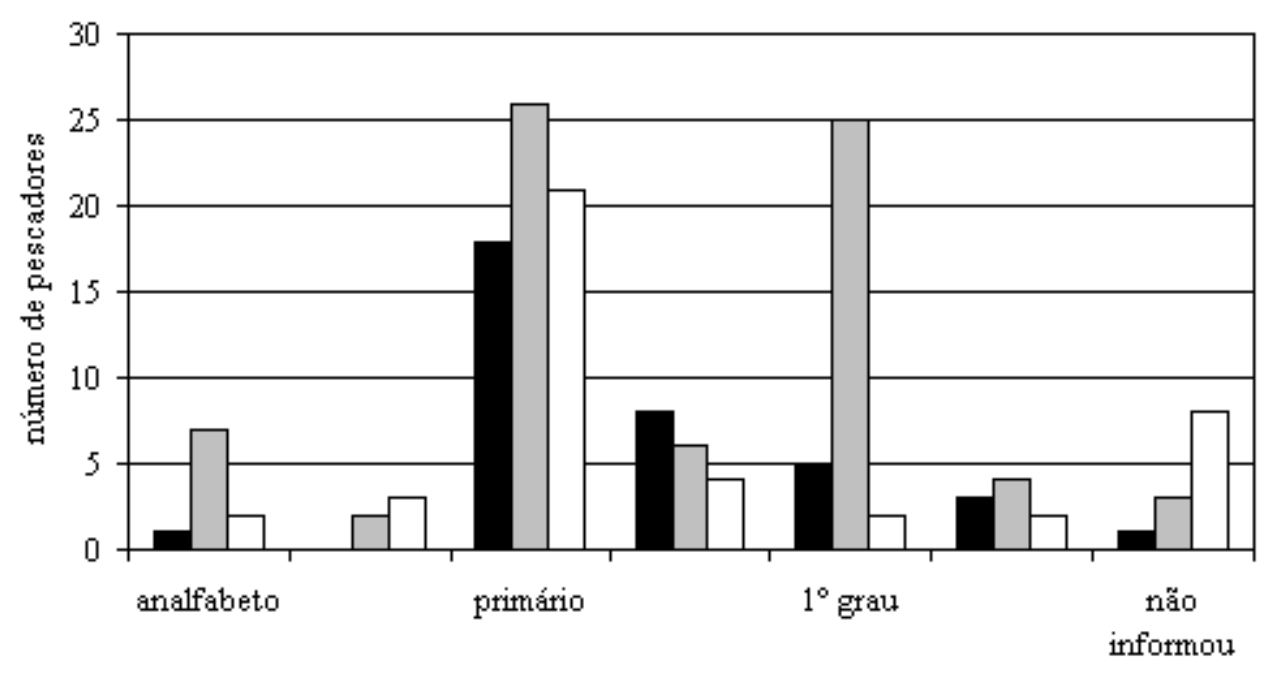

escolaridade

Ambiente $1 \square$ Ambiente $2 \square$ Ambiente 3

Figura 3. Freqüências dos pescadores segundo o grau de escolaridade, nos três ambientes considerados. Ambiente 1: reservatórios de Ilha Solteira e Jupiá; Ambiente 2: trecho do rio Paraná entre as barragens de Jupiá e Porto Primavera; Ambiente 3: trecho do rio Paraná a jusante da barragem de Porto Primavera.

Os analfabetos correspondem a 5,5\% dos entrevistados. Esse valor é superior ao obtido para o reservatório de Segredo, que é de 3,4\% (OKADA et al., 1997), porém, inferior aos $11 \%, 45,5 \%$ e $20 \%$ obtidos, respectivamente, para o reservatório de Itaipu (AGOSTINHO et al., 1994(b)), rio São Francisco (CAMARGO, 1998) e reservatórios de Jurumirim/Barra Bonita (MENDONÇA, 2000). Pescadores que sabem apenas ler e escrever o nome, correspondem a $3,4 \%$ dos entrevistados. Observou-se que, nos três ambientes, independentemente da época considerada, há predomínio do primário ou $1^{\circ}$ grau (completo ou incompleto), indicando situação semelhante aos reservatórios de Itaipu, com 68,8\% dos pescadores (AGOSTINHO et al., 1994(b)), Segredo, que conta com 76\% dos pescadores tendo primário completo (OKADA et al., 1997), e rio São Francisco, com 51,5\% (CAMARGO, 1998).

Segundo FIRTH (1998), a educação é mais efetiva quando combinada com a descoberta e, por outro lado, a descoberta é muito mais gratificante quando "casada" com a educação. Portanto, como há uma certa deficiência na instrução dos pescadores, este fato pode se reverter em uma resistência ao emprego de novas tecnologias para o desenvolvimento da pesca em águas continentais do Estado de São Paulo. Além disso, os pescadores se vêem sem alternativa para a busca de outra atividade caso a pesca decline. Outra conseqüência da baixa instrução pode se refletir no momento da negociação do pescado: o pescador, com baixa instrução, pode não ter controle efetivo sobre sua 
produção e, com isso, ser prejudicado no momento da venda de seu produto.

Assim como não há restrição de idade para seu o exercício, a pesca é uma atividade que pode ser praticada durante o ano todo, porém, existem períodos nos quais o retorno não é satisfatório. Segundo os pescadores, independentemente do ambiente considerado, os meses favoráveis para a pesca se estendem de outubro a março (período bom para a pesca). A maioria deles afirma que durante os meses de junho, julho e agosto, a produtividade pesqueira declina (período ruim para a pesca). É possível associar esses períodos com as duas épocas das entrevistas: o período "bom para a pesca" corresponde à época classificada como chuvosa e quente e o período "ruim para a pesca" é a chamada época seca e fria. Os meses de abril, maio e setembro podem ser chamados "períodos de transição" pois não foram muito citados pelos pescadores, nem como meses bons nem ruins para a pesca. Porém, em levantamento feito pelo Instituto de Pesca (SANTOS et al., 1995), 41\% dos pescadores entrevistados no Estado de São Paulo informaram que o período que compreende os meses de março a setembro é o mais favorável à pesca. Essas diferenças de resultados obtidos refletem a desorganização ou inconsistência dos levantamentos de dados pesqueiros no território nacional.

Essas diferenças sazonais também foram observadas nas pescarias artesanais de pequena escala realizadas no rio Piracicaba: a composição e a quantidade das espécies capturadas variam, bem como as estratégias de pesca. Essas alterações sazonais reduzem as pressões sobre apenas algumas espécies, ao longo do ano todo, possibilitando que a explotação não seja tão acentuada sobre os estoques de peixes existentes (SILVANO \& BEGOSSI, 2001).

Quando se leva em conta a época seca, na qual há declínio da produção pesqueira, os pescadores se vêem forçados a buscar uma fonte alternativa (e temporária) de renda. De acordo com as entrevistas é possível afirmar, estatisticamente, que a busca por outra atividade no período de seca depende do ambiente e da época considerada. Sendo assim, observa-se na época seca que, à medida que se desce o rio Paraná, a busca por outra atividade aumenta: $17,6 \%, 21,9 \%$ e $36,4 \%$ dos pescadores dos ambientes 1,2 e 3 , respectivamente, buscam uma atividade no período "ruim" da pesca, a fim de complementar sua renda (Tabela 1).

Tabela 1. Distribuição de freqüências observadas e esperadas dos pescadores que exercem outra atividade no período de entressafra da pesca, nos três ambientes considerados. Ambiente 1: reservatórios de Ilha Solteira e Jupiá; Ambiente 2: trecho do rio Paraná entre as barragens de Jupiá e Porto Primavera; Ambiente 3: trecho do rio Paraná a jusante da barragem de Porto Primavera. 


\begin{tabular}{|c|c|c|c|c|c|c|}
\hline \multirow{3}{*}{$\begin{array}{l}\text { atividade } \\
\text { na } \\
\text { entressafra } \\
\text { da pesca? }\end{array}$} & \multicolumn{3}{|c|}{ Época Seca } & \multicolumn{3}{|c|}{ Época Chuvosa } \\
\hline & \multicolumn{3}{|c|}{ Ambientes } & \multicolumn{3}{|c|}{ Ambientes } \\
\hline & 1 & 2 & 3 & 1 & 2 & 3 \\
\hline Sim & $3(2,29)$ & $7(4,32)$ & $8(2,97)$ & $\| 2(2,43)$ & $\|2(5,53)\|$ & $0(4,45)$ \\
\hline Não & $\begin{array}{r}14 \\
(14,70)\end{array}$ & $\begin{array}{r}25 \\
(27,68)\end{array}$ & $\mid \begin{array}{r}14 \\
(19,03)\end{array}$ & $\mid \begin{array}{r}16 \\
(15,57)\end{array}$ & $\begin{array}{r}39 \\
(35,47)\end{array}$ & $\begin{array}{r}33 \\
(28,55)\end{array}$ \\
\hline Total & 17 & 32 & 22 & 18 & 41 & 33 \\
\hline
\end{tabular}

A maior previsibilidade do pescado, no ambiente das represas, contribui para que os pescadores desse tipo de ambiente se dediquem apenas à pesca, mesmo na época considerada seca.

Dentre as outras atividades exercidas na entressafra da pesca foram citadas: jardinagem e servente de pedreiro como as mais procuradas pelos pescadores. Observa-se que são atividades de curta duração e que não exigem maiores qualificações por parte de quem a pratica. Porém, conforme relatado pelos próprios pescadores, não é muito fácil conseguir trabalho pois eles têm que competir com pessoas que já exercem essas atividades, não só na entressafra da pesca como também durante o ano todo, por se tratar de fonte de renda principal para essas outras pessoas.

Em relação aos equipamentos de pesca, verificou-se que nos ambientes 1 e 2 predominam as embarcações feitas de alumínio e no ambiente 3 prevalecem as de madeira. Essa diferença do tipo de material com o qual é confeccionada a embarcação depende do ambiente $\left(\mathrm{X}^{2}=13,87>z_{2: 0,05}^{2}=5,99\right)$. Com relação à presença (ou ausência) de motor, $90,8 \%$ do total de entrevistados possui motor em suas embarcações, para se deslocar. A presença (ou ausência) de motor na embarcação não depende do ambiente no qual o pescador atua $\left(\mathrm{X}^{2}=4,71<\chi_{20,05}^{2}=5,99\right)$. Em ambas as coletas, $100 \%$ dos pescadores das represas têm motor, evidenciando a necessidade de percorrer longas distâncias em busca de locais mais piscosos para a prática da sua atividade. Além disso, o fato de todos os pescadores possuírem motor de popa, possibilita deslocamentos mais rápidos nos reservatórios. Nos outros dois ambientes, a grande maioria possui motor, porém ainda existem pescadores que se deslocam a remo. Situação contrária à obtida nesse estudo foi verificada nos reservatórios de Salto Santiago e Salto Osório, onde apenas 34\% dos pescadores utilizam motor em suas atividades: $33 \%$ têm motor tipo rabeta e apenas $1 \%$ dos pescadores têm motor de popa, haja vista que apenas $6 \%$ dos pescadores nesses reservatórios têm a pesca como atividade prioritária na formação de sua renda,pois a peca é considerada ilegal no rio Iguaçu (OKADA et al., 1997). 
Durante as entrevistas, muitos pescadores comentaram a respeito da dificuldade em adquirir bons motores e barcos, de modo que seu trabalho seja mais constante, nos diferentes ambientes em que atuam. A ineficiência de algumas colônias em tratar de assuntos como financiamentos e empréstimos geram, muitas vezes, insatisfação nos pescadores, que acabam optando por não pertencer a nenhuma colônia e passam a ser considerados "pescadores ilegais".

Durante a primeira coleta de dados (julho/98), houve manifestação, por parte de pescadores da região a jusante da barragem de Porto Primavera, em relação à criação de uma cooperativa, visando um melhor ordenamento e gerenciamento da pesca, de modo a evitar tamanha imprevisibilidade no retorno financeiro da atividade. Porém, ao retornar para a segunda coleta, em fevereiro/99, a idéia da cooperativa não havia saído do papel. Esse fato isolado evidencia a falta de conhecimento e tradição entre os pescadores para vivenciar uma experiência desse porte.

$\mathrm{Na}$ tabela a seguir estão apresentados os dados referentes ao número de dias que o pescador pratica sua atividade, durante a semana.

Tabela 2. Distribuição de freqüências observadas e esperadas dos pescadores em relação ao número de dias que pesca durante a semana, nos três ambientes considerados. Ambiente 1: reservatórios de Ilha Solteira e Jupiá; Ambiente 2: trecho do rio Paraná entre as barragens de Jupiá e Porto Primavera; Ambiente 3: trecho do rio Paraná a jusante da barragem de Porto Primavera.

\begin{tabular}{|c|c|c|c|c|c|c|}
\hline \multirow{4}{*}{$\begin{array}{c}\text { Dias que pesca } \\
\text { Durante a } \\
\text { semana }\end{array}$} & \multicolumn{6}{|c|}{ Número de pescadores } \\
\hline & \multicolumn{3}{|c|}{ Época Seca } & \multicolumn{3}{|c|}{ É́poca Chuvosa } \\
\hline & \multicolumn{3}{|c|}{ Ambientes } & \multicolumn{3}{|c|}{ Ambientes } \\
\hline & 1 & 2 & 3 & 1 & 2 & 3 \\
\hline 4 & $\begin{array}{c}1 \\
(1,00)\end{array}$ & $\begin{array}{c}3 \\
(1,90)\end{array}$ & $\begin{array}{c}1 \\
(1,51)\end{array}$ & $\begin{array}{c}1 \\
(1,49)\end{array}$ & $\begin{array}{c}4 \\
(2,84)\end{array}$ & $\begin{array}{c}1 \\
(2,26)\end{array}$ \\
\hline 5 & $\begin{array}{c}2 \\
(2,27) \\
\end{array}$ & $\begin{array}{c}4 \\
(4,32) \\
\end{array}$ & $\begin{array}{c}11 \\
(3,44)\end{array}$ & $\begin{array}{c}1 \\
(3,39) \\
\end{array}$ & $\begin{array}{c}2 \\
(6,44)\end{array}$ & $\begin{array}{c}5 \\
(5,13) \\
\end{array}$ \\
\hline 6 & $\begin{array}{c}0 \\
(1,73)\end{array}$ & $\begin{array}{c}6 \\
(3,28)\end{array}$ & $\begin{array}{c}1 \\
(2,62)\end{array}$ & $\begin{array}{c}2 \\
(2,57)\end{array}$ & $\begin{array}{c}7 \\
(4,90)\end{array}$ & $\begin{array}{c}3 \\
(3,90)\end{array}$ \\
\hline 7 & $\begin{array}{c}13 \\
(7,45)\end{array}$ & $\begin{array}{c}8 \\
(14,18)\end{array}$ & $\begin{array}{c}5 \\
(11,29)\end{array}$ & $\begin{array}{c}11 \\
(11,11)\end{array}$ & $\begin{array}{c}25 \\
(21,14)\end{array}$ & $\begin{array}{c}20 \\
(16,84)\end{array}$ \\
\hline Total & 16 & 21 & 18 & 15 & 38 & 29 \\
\hline
\end{tabular}




$$
\mathrm{X}^{2}=41,38 ; \chi_{1770,05}^{2}=27,59
$$

O número de dias na semana que o pescador pratica sua atividade pode ser considerado como uma das medidas do esforço de pesca do mesmo, conceito que está diretamente ligado à produtividade do pescador. Para o Estado de São Paulo, SANTOS et al. (1995) estimaram em 47,94\% os pescadores que pescam de 26 a 30/31 dias no mês, enquanto que no rio São Francisco, a média de dias pescados por semana foi de 6,2 e 5,8 para as épocas chuvosa e seca, respectivamente (CAMARGO, 1998). Os pescadores dos ambientes 1 e 2 , em sua maioria, pescam diariamente. No ambiente 3 , durante a $1^{\mathrm{a}}$ coleta, predominou a pesca em 5 dias, enquanto que na $2^{\text {a }}$ coleta, a maioria dos pescadores informaram pescar diariamente. Estatisticamente, pode-se afirmar que existe alguma relação entre o número de dias que o pescador exerce sua atividade e o ambiente no qual atua e a época $\left(\mathrm{X}^{2}=41,38>\chi_{17 ; 0,05}^{2}=27,59\right)$. Essa diferença de comportamento em relação aos ambientes é reflexo do fator hidrológico: na época seca, os pescadores de rio têm maiores dificuldades em exercer sua atividade, buscando outras atividades e diminuindo o número de dias de pesca. Já no período chuvoso, o retorno da pesca é visto como "certo" o que incentiva os pescadores a praticarem a pesca quase que diariamente no Ambiente 3.

Os aparelhos utilizados na pesca e citados pelos pescadores são utilizados individualmente ou combinados entre si. Na Tabela 3 estão apresentados os aparelhos citados individualmente pelos pescadores.

Tabela 3. Distribuição de freqüências dos pescadores em relação aos aparelhos utilizados na atividade pesqueira, nos três ambientes considerados. Ambiente 1: reservatórios de Ilha Solteira e Jupiá; Ambiente 2: trecho do rio Paraná entre as barragens de Jupiá e Porto Primavera; Ambiente 3: trecho do rio Paraná a jusante da barragem de Porto Primavera.

\begin{tabular}{|c|c|c|c|c|c|c|}
\hline \multirow{4}{*}{$\begin{array}{c}\text { Aparelhos de } \\
\text { pesca }\end{array}$} & \multicolumn{6}{|c|}{ Número de pescadores } \\
\hline & \multicolumn{3}{|c|}{ Época Seca } & \multicolumn{3}{|c|}{ Época Chuvosa } \\
\hline & \multicolumn{3}{|c|}{ Ambientes } & \multicolumn{3}{|c|}{ Ambientes } \\
\hline & $\mathbf{1}$ & 2 & 3 & 1 & 2 & 3 \\
\hline Tarrafa & 0 & 2 & 1 & 0 & 6 & 0 \\
\hline Rede de espera & 7 & 6 & 5 & 11 & 17 & 4 \\
\hline Espinhel & 0 & 1 & 6 & 0 & 0 & 12 \\
\hline Vara/molinete & 0 & 0 & 0 & 0 & 2 & 3 \\
\hline
\end{tabular}

Na bacia do Alto rio Paraná, as redes de espera são os equipamentos mais 
utilizados (CESP, 1996). Esse resultado é confirmado aqui, pois observou-se que no ambiente 1, nas duas épocas, há o predomínio das redes de espera, utilizadas como único aparelho pelos pescadores $\left(41,2 \%\right.$ e $57,9 \%$ na $1^{\mathrm{a}}$ e $2^{\mathrm{a}}$ coletas, respectivamente). Se forem consideradas as combinações de rede de espera com outros aparelhos, essa porcentagem sobe para $94,1 \%$ na primeira coleta, e $73,7 \%$ na segunda coleta. Quanto ao ambiente 2, além das redes de espera serem utilizadas como único aparelho de pesca $(18,9 \%$ e $41,5 \%$ na $1^{\mathrm{a}}$ e $2^{\mathrm{a}}$ coletas, respectivamente), ainda há aqueles pescadores que utilizam dois tipos de aparelhos: redes de espera e tarrafas $\left(18,9 \%\right.$ na $1^{\mathrm{a}}$ coleta e $12,2 \%$ na $2^{\mathrm{a}}$ coleta). No ambiente 3 , o aparelho predominante é o espinhel $\left(27,4 \%\right.$ e $36,4 \%$ da $1^{\mathrm{a}}$ e $2^{\mathrm{a}}$ coletas, respectivamente).

Como reflexo da multiplicação das barragens em todo Estado de São Paulo, a tendência é que haja um aumento do uso de redes por parte dos pescadores, pois a presença de grandes áreas lênticas favorece o uso de tal equipamento em detrimento dos demais, como espinhel e vara/molinete. Além disso, o uso de redes de espera é uma característica de ambientes nos quais não há formação de cardumes, como é o caso, em geral, dos reservatórios.

Assim, a pesca considerada como atividade econômica deve promover a equidade e que esta depende da instrução do pescador, e as desigualdades de renda detectadas entre OKADA et al. (1997) e AGOSTINHO et al. (1994(b)) e este trabalho se encaixa no raciocínio de DAILY \& EHRLICH (1996) e FIRTH (1998), onde discutem o efeito de políticas públicas educacionais sobre a renda das populações menos favorecidas.

Segundo BRETON (1991), as comunidades de pescadores podem ser consideradas como grupos sociais relativamente homogêneos mas, é necessário entender seus componentes internos pois, dependendo das variáveis consideradas 0 desenvolvimento de projetos pode levar a diferentes hipóteses e soluções concretas. Os resultados, muitas vezes restritos, obtidos em vários projetos desenvolvidos em comunidades pesqueiras, alertam para a necessidade de se alargar a visão da dimensão social da pesca.

\section{CONCLUSÕES}

A pesca interior é uma atividade que não recebe incentivos por parte do Governo e, portanto, dados referentes à atividade são escassos e, muitas vezes, inconsistentes.

Os pescadores que atuavam no leito do rio Paraná foram, pouco a pouco, tendo que se adaptar ao novo ambiente formado pelos reservatórios das grandes barragens construídas ao longo do rio. 
A maioria dos pescadores entrevistados tem a pesca como atividade principal, a despeito da baixa lucratividade. Porém, em época de seca, tendem a complementar sua renda com diferentes atividades além da pesca.

Ao longo da História, o manejo de recursos tornou-se uma disciplina repleta de fracassos, devido à incontestável contradição existente entre o desejo e a capacidade humana. Apesar dessa sucessão de fracassos, raramente os profissionais mudam suas políticas frente às respostas de experiências passadas (LUDWIG, 1993). A carência de conhecimento e a inabilidade em criar políticas que antecedam a exploração desordenada dos recursos são um fato (LUDWIG et al., 1993).

A falta de conhecimento e a inabilidade para criar políticas que antevejam a exploração desenfreada de recursos, são normais (LUDWIG et al., 1993). Porém, algumas medidas podem ser tomadas, para atenuar as discrepâncias entre a exploração e o manejo dos recursos. Preservar o último trecho do rio Paraná com suas características lóticas é necessário, mas também é preciso políticas de organização e manejo dos ambientes que foram alterados pelos reservatórios construídos, de modo a preservar os recursos e garantir uma exploração adequada dos mesmos.

\section{REFERÊNCIAS}

AGOSTINHO, A. A.; JÚLIO JR H. F.; PETRERE JR, M. Itaipu reservoir (Brazil): impacts of the impoundment on the fish fauna and fisheries. In: Rehabilitation of Freshwater Fisheries, Fishing News Books. Bodmin: I. G. Cowx, 1994(a). p.171184.

AGOSTINHO, A.A.; OKADA, E.K.; GREGORIS, J. Características Econômicas e Sociais das Atividades Pesqueiras no Reservatório de Itaipu. In: SIMPOSIO REGIONAL SOBRE MANEJO DE LA PESCA EM EMBALSES EM AMERICA LATINA. Havana: FAO/COPESCAL, 1994(b). 100p. (Publicaciones Técnicas).

AGRESTI, A. Analysis of ordinal categorical data. New York: John Wiley \& Sons, 1984. 287p.

BARRELLA, W. et al. As relações entre as matas ciliares, os rios e os peixes. In: RODRIGUES, R. R.; LEITÃO FILHO, H. F. (eds). Matas Ciliares: Conservação e Recuperação. São Paulo: Editora da Universidade de São Paulo: FAPESP, 2000. p.187-207.

BAYLEY, P. B. Accounting for effort when comparing tropical fisheries in lakes, riverfloodplains, and lagoons. Limnology and Oceanography, v. 33 (4 part 2), 1988. 
p.963-972.

BONETTO, A. A. The Paraná river system. In: DAVIS, B. R.; WALKER, K. F. (eds). The ecology of river systems. The Netherlands: Dr. Junk Pub., 1986. p.541-556.

BRETON, Y. Economic anthropology and interdisciplinarity in Costa Rica fishing. MAST - Maritme Anthropological Studies, v. 3, no 1, 1991. p.1-12.

CAMARGO, S. A. F. Sociobiologia da gestão participativa dos pescadores comerciais do rio São Francisco, MG, Brasil. 1998. 122 f. Dissertação (Mestrado em Conservação e Manejo de Recursos, Área de Concentração: Gestão Integrada de Recursos) - Centro de Estudos Ambientais, UNESP, Rio Claro.

CESP. Aspectos limnológicos, ictiológicos e pesqueiros de reservatórios da CESP no período de 1986 a 1994. São Paulo: CESP, 1996. 81p. (Série Pesquisa e Desenvolvimento, 136).

CHAGAS, A. L. G. A. Pesca de águas interiores. In: SEMINÁRIO SOBRE A FAUNA AQUÁTICA E O SETOR ELÉTRICO BRASILEIRO - REUNIÕES TEMÁTICAS PREPARATÓRIAS, 1994, Curitiba. Rio de Janeiro: COMASE/ELETROBRÁS, 1994. p.14-23. (Caderno 3 - Conservação da fauna aquática).

DANIEL, W. W. Biostatistics - A foundation for analysis in the health sciences. 6 . ed. New York: John Wiley \& Sons, 1995. 780p.

DAILY, G. C.; EHRLICH, P. R. Socioeconomic equity, sustainability, and Earth's carrying capacity. Ecological Applications, v. 6, no 4, 1996. p. 991-1001.

ENCYCLOPAEDIA BRITANNICA. 15. ed. Macropaedia. 13, 1981. p.999-1001.

EVERITT, B. S. The analysis of contingency tables. London: Chapman and Hall Ltd., 1977. 128p.

FIRTH, P. L. Freshwater: perspectives on the integration of research, education, and decision making. Ecological Applications, v. 8, nº 3, 1998. p.601-609.

HARDIN, G. The tragedy of the commons. Science, v. 162, 1968. p.1243-1248.

LEONEL, M. A morte social dos rios. São Paulo: Perspectiva: Instituto de Antropologia e Meio Ambiente: FAPESP, 1998. 263p. (Coleção Estudos, 157).

LUDWIG, D. Environmental sustainability: magic, science, and religion in natural resource management. Ecological Applications, v. 3, $\mathrm{n}^{\mathrm{o}} 4$, 1993. p.555-558. 
LUDWIG, D.; HILBORN, R.; WALTERS, C. Uncertainty, resource exploitation, and conservation: lessons from History. Ecological Applications, v. 3, $\mathrm{n}^{\mathrm{o}} 4$ 4, 1993. p.547549 .

MARSHALL, B. E. Predicting ecology and fish yields in African reservoirs from preimpoudment physicochemical data. CIFA Tech. Pap./Doc. Tech. CPCA 12, 1984. p.1-26.

MENDONÇA, S. A. T. Pescadores-barrageiros: perfil profissional e condições de vida no interior paulista. 2000. 119 f. Dissertação (Mestrado em Conservação e Manejo de Recursos, Área de Concentração: Gestão Integrada de Recursos) - Centro de Estudos Ambientais, UNESP, Rio Claro.

NAIMAN, R. J.; TURNER, M. G. A future perspective on North America's freshwater ecosystems. Ecological Applications, v. 10, no 4, 2000. p.958-970.

OKADA, E.K. et al. Diagnóstico da pesca profissional em dois reservatórios do rio Iguaçu. In: AGOSTINHO, A. A.; GOMES, L. C. Reservatório de Segredo: Bases Ecológicas para o Manejo. Maringá: Editora da Universidade de Maringá, 1997. P.293-318.

PAIVA, M. P. Grandes Represas do Brasil. Brasília: Editerra, 1982. 292p.

PAIVA, M. P. et al. Relationship between the number of predatory fish especies and fish yield in large North-eastern Brazilian reservoirs. In: Rehabilitation of Freshwater Fisheries, Fishing News Books. Bodmin: I. G. Cowx, 1994. p.120-129.

PETRERE, M. River fisheries in Brazil: a review. Regulated rivers: research an management, v. 4, 1989. p.1-16.

PETRERE, M. As comunidades humanas ribeirinhas da Amazônia e suas transformações sociais. In: IV ENCONTRO DE CIÊNCIAS SOCIAIS E O MAR NO BRASIL. São Paulo: PPCAUB-USP, 1990. p.31-68.

PETRERE, M. A pesca de água doce no Brasil. Ciência Hoje, v. 19, nº 110, 1995. p.2833.

PETRERE, M. Fisheries in large tropical reservoirs in South America. Lakes \& Reservoirs: Research and Management, v. 2, 1996. p.111-133.

PETRERE, M. et al. Review of fisheries in the Brazilian portion of the Paraná/Pantanal basin, 1998.

PETRERE, M.; AGOSTINHO, A. A. La pesca en el tramo brasileño del rio Parana. FAO - Informe de Pesca, 490, 1993. p.52-72. 
ROSA, L.P. et al. Estado, energia elétrica e meio ambiente : o caso das grandes barragens. Rio de Janeiro: Editora da UFRJ e Setor de Publicações e programação visual/COPPE, 1995. 182p.

SANTOS, R. A. et al. Considerações sobre a pesca profissional e a produção pesqueira em águas continentais do Estado de São Paulo. São Paulo: Instituto de Pesca, Coordenadoria da Pesquisa Agropecuária, 1995. 32p. (Boletim Técnico, 19).

SILVANO, R. A. M.; BEGOSSI, A. Seasonal dynamics of fishery at the Piracicaba River (Brazil). Fisheries Research, vol. 51, Iss 1, 2001. p.69-86.

SIMPSON, R. D. Economic Analysis and ecosystems: some concepts and issues. Ecological Applications, v. 8, $\mathrm{n}^{\circ}$ 2, 1998. p.342-349.

TORLONI, C. E. C. et al. Produção pesqueira e composição das capturas em reservatórios sob concessão da CESP nos rios Tietê, Paraná e Grande no período de 1986 a 1991. São Paulo: CESP, 1993. 73p. (Série Produção Pesqueira, 001).

WILSON, M. A.; CARPENTER, S. R. Economic valuation of freshwater ecosystem services in the United States: 1971-1997. Ecological Applications, v. 9, no 3, 1999. p.772-783.

\footnotetext{
* Após cisão parcial da CESP foram formadas: uma empresa de transmissão (Companhia de Transmissão de Energia Elétrica Paulista) e duas de geração de energia (Companhia de Geração de Energia Elétrica Tietê e Companhia de Geração de Energia Elétrica Paranapanema)
}

\section{ANEXO I - MODELO DE QUESTIONÁRIO UTILIZADO NA COLETA DE DADOS}




\section{QUESTIONÁRIO}

Local:

\section{A - IDENTIFICAÇĀO DO PESCADOR}

1. NOME:

2. IDADE: anos

3. Egratx) CIVIL

[ sciteiro $]$ casado

L vi uvo

I. separado

I outro. Quel?

4. GRAU DE INSTRIJZ\%O

$\exists$ analfabeta

$\square$ nås estudou, ras sabe ler e escrever

J primário incompleto

$\square$ primáío completo

7 ginásio incompleto

L ginásio completo

$1^{\circ} \mathrm{grau}$

$2^{\circ} \mathrm{grau}$

[ incumpleto

L complets

$\square$ cursando

superior

I incompleto

a complete

1 cursando

profissionalizante

C inconpleto

] completo

[ cursando

profissionalizante

I) incompleto

J completo

[. cursando

5.E FILIADO A ALGUMA CCLÓNIA? L não

$\neg \mathrm{sim}$. Qua1?

\section{B - CONDIÇÕES DE MORADIA}

\section{O DOMICILIO}

1. SUA CASA É: $\square$ própric $\square$ alugacia $L$ cedida $\sqsupset$ outro. Qualz

2. AREA CONSTRUADA DO DOMICILIO: $\mathrm{m}^{2}$

3. MATERIAL, DO QUAL È FEITO:

\section{PAREDES}

1] alvenaria

$\square$ madeira

C pan-a-pique

] outro

\section{TELAADO}

$\square$ tolha de barro

I madeira

[ zinco ou fibrocimento

Г. sape ou palha

ᄃ outro
PISO

$\checkmark$ madeina

$\square$ ledrilho

$\square$ terra batida

L cimento/tijolo

Coutro

\section{II . FONTE DE ENERGIA}

4. A ENERGIA CONSJMIDA EV SUA CASA VEM DE ONDE?

[ rede piblica I própria (cata-vento, gerador, pequena hidroelètzica)

[ lampiăo/vela

- Outras, Quais?

\section{III . SANEAMENTO BÁSICO}

5. ABASTECIMENTO EN SUA RESIDENCIA E FETTO ATRAVÉS DE:
7 recie püblica
] poço
L rio
] reservatório
rascente
[ olho d'água $\square$ lago 
6. QJAL O TRATAMENTO DACO A AGUA UTILIZADA:
口 filtrada
(7) fervida
L. nå faz nada
$\beth$ outro. Qual?

7. SEU DOMICILIO POSSUI INSTÃLAÇÖES SANITARIAS?

D sim

$\square$ dentro de casa

$-\square$ nå

․ fora de casa

8.O SISTEMA LE ESGOTO É ATRAVES DE:

$\square$ rede pública $\square$ fossa comur.

U vala negra $\quad$ direto no curso d'água

[. outro, oual?

9. QUAL O DESTINO DO LIXO DA SUA CASA?

$\square$ coletado por caminhbes $I$ queimado

0 enterrado $[$ jogado em terrenos baldios

7 jogado no rio/reservatorio $\square$ outro. Qual?

\section{A FAMÍLIA}

1. QUANTAS PESSOAS VIVEM SOB SUA RESPCNSABILIDARE? (indicar as quantidades)

$\square$ esposa (marido) $[$ filhos $\square$ genro/nora $\square$ metos $]$ pais

¿ tios $\quad$ primos

[ sogro/sogra

J agregados

2. BENS DA FAMILIA (indicar a quantidade)

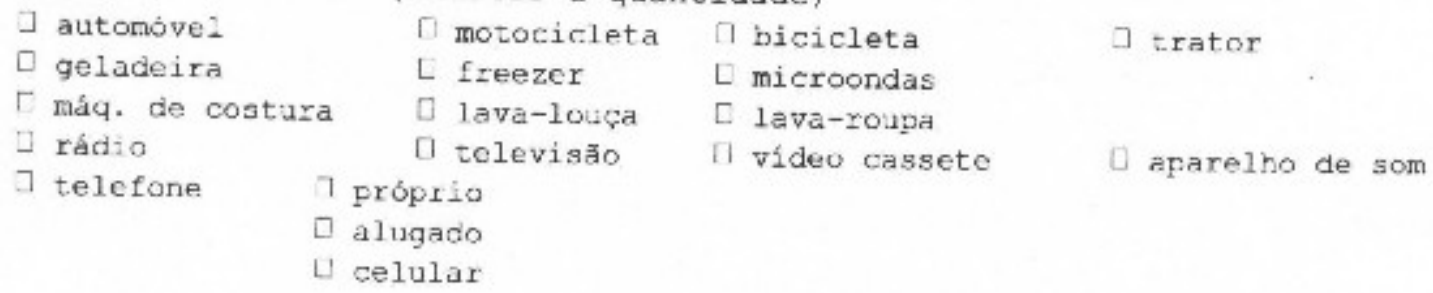

\section{D.SITUAÇÃO DO MEIO AMBIENTE}

1.0 LUGAR QUE O SR. PESCA/VZVE ESTÁ: П inallerado, polo menos nos últimos 10 anos

$\square$ moderadamente degradadio

I degradiado

ㄱ seriamente degradado

2. EXISTE PESCA ESPORTIVA (AMADOEA) NO BNOORNO?
กลั่
$\square \operatorname{sim}$

3. CONSILERA OUE A PESCA ESFORTIVA (AMADORA) PFETA A CCMUNIDADE RESIDFNTE NO LOCAL?

7 positivamente

L negativarente
mitito
1 pouco
[ nå ateta

(1) nao sabe

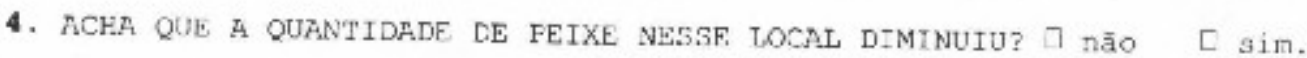

5. A CAUSA É:

L m.uita pesea

$\sqsupset$ puluicso

I pesca andaciora

7 outros 


\section{B.A ATIVIDADE PESQUEIRA}
1. SEMPFE FOI PESCALCR?
$\square \sin \Gamma$ rå.

2.O QUE EAZIA ANTES DE SER PESCAIYOR?

3. LOCAL ONDE ATUA COMO PESCADCR:

Z r10 7 reservatório $\square$ ambos 7 outros. Qual?

4. HA QUANTO TEMPC PESCA NESTE LOCAI? anos

5. SEMPRE PESCCU NESTE IOCAL?

Dim [ nas.

6. ONLE PESCAVA ANTES?

Tempo: anos

7. TEM MAIS ALGUÉM NA EAMILIA CUE PARTICIPA DA ARIVIDADE PESQUEIRA?
U) naิo
aim
tanióm pescam
$\exists$ ajudante de pesca
u verde peixc
U sutro. 0 qué?

8.EXISTFM QUANTCS PESCADORES ATUANDO NESSE VESMO LCCAL, QLE O GENHOR?

9. CONSEGUE SUSTENTAR A FAMILIA S6 COM A PESCA? U sim nấ

10. PRETENDE CONTZNUAR NESSA ATIVIDADE? $\square$ nå

11. DESEJA OUE CS FILHOS PERMANECAY NESEA ATIVIDADE? $\square$ sim

12. OS EILHOS PRETENCEN SE MANTER MESSA ATIVIDALE? J sim

13.TEM OUTRA OCUPAÇÑO? J năo IIm. Qual?

14. QUAL SUA ATTVIONDE NA ENTRESGAFRA DA DESCA?

15. RECEITA MENSAL CON OUTRAS ATIVIDADES (exoluindo a pesca):

16. RFNDA MENSAL DA EAMILIÄ (envolvento todos os nexbros e atividades):

\section{F.EQUIPAMENTOS DE PESCA}

\section{BARCO}

1.MATERIA二

I madeira 4 fihra 7 aluminio 4 compensade $\square$ outros

2. COMPRIMENZO: metros

3. PROCEDENCIA

(4) proprio $I$ a-uyaco $L$ emorcstacio $[$ arrendado $I$ peixeiro $\square$ outros

\section{II.SISTEMA DE IMPULSÄO}

4. ESFECIFICAÇÃO

[ reno (sem motor)

$\square$ totossezrd (5H:P) ]

(1) rabeta $(3,4 \mathrm{~Hz})$

$\square$ centro ig-11): $\square$ cascude (4HF)

$\checkmark$ pope $(15-25 \mathrm{HF})$ 
5. Consumo iespecificar a perivdicidace do consurmo: diário, semaral, mensal, etc.)

\begin{tabular}{|l|l|l|}
\hline If-po de combustivel & Consuno/litros & Preço do litro \\
\hline & & \\
\hline & & \\
\hline & & \\
\hline
\end{tabular}

III. CUSTOS COM A EMRARCAÇ̄̃o

Alugucl
*especificer a periodicidade com que taz marutença e a pagamento do aluguel

6. CUANTO TEMPO DURA O EARCO?

7. HA QUANTC IEMPC O SR. POSSUT ESSF RARCO?

8.0 SR. PRETENDE TROCA-ZO? П rË०

I sim, Quando?

\section{G. APARELHOS DE PESCA}

1. PROCEDÊNCT मे
$\square$ proprio 7 alugado
$\square$ exprestado
[ arrendado
$U$ peixeiro
I ouras

2. TIPOS

\section{TARRAFA}

Quant alt roda ralha quanto custa? Quanto dura? Manutença

\section{II.REDE DE ESPERA}

Quantidare

\begin{tabular}{|c|c|c|c|c|c|c|c|}
\hline simples & feit & ralha & comp & alt & custa? & Dura? & Manutenção \\
\hline & & & & 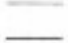 & $\bar{u}$ & & \\
\hline & & $\longrightarrow$ & $\longrightarrow$ & - & + & - & 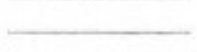 \\
\hline
\end{tabular}

\section{III.ESPINHÉ IS}

número de canos:

Custo mitário: nimero de anzóis: manutençăo: tamarino dos anzóis: durarao:

IV.oumRos: $\square$ linhadas $\Pi$ espera $\perp$ fisga $\rfloor$ covo $\square$ vara de pesca 


\section{H. A PESCA}

1. FINALIIJADE DO PESCADO: $\Pi$ so consLmo $I$ so venda $\quad[$ consumo e venda

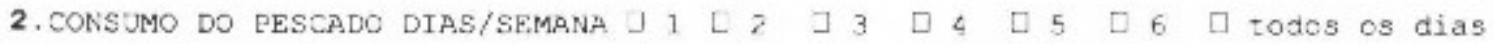

3. CONO CONSERVA P PESCADO? $I$ a tresco $\Pi$ no gelo $\Pi$ congelador

$\exists$ salgaicharque $\square$ cutros. Quais

4. OUATS OS CUSTOS COM A CONSERVAÇAO DO PESCADO?

5. QUAIS A.S ESPECIES QUE PRE ZERE CAPTURAR?

POP. QUE?

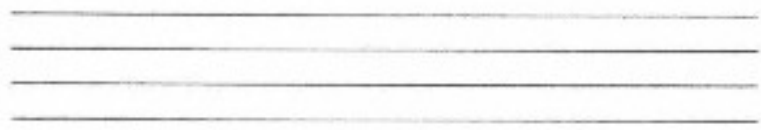

6. QUAIS-ESPECIES CUE RAC GOSTA DE CAPTURAR?

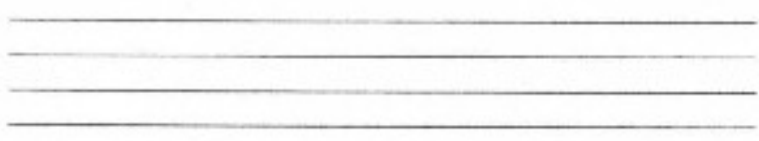

7. QUAIS CS MELHCRES: MESUES FARA A PESCA:

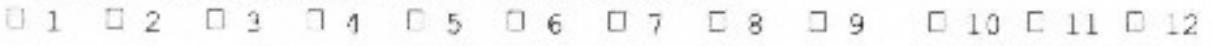

8.NO PER TCCO "BCY", QUNNTOS QUIZOS CAPTURA MENSATNFNTE?

Máximo: $\mathrm{Kg} \mathrm{Minima:}$

$\mathrm{Kg}$

9.OUAIS OS PIORES MEEES PARA A PESCA?

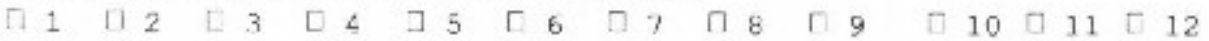

10. NC PERIODO "RUTM", COANTOS QUILOS CAETURA VENSALMENTE?

Méxime: $\mathrm{Kg}$ Minino: $\mathrm{Kg}$

11. OUANTOS DIAS O SENHOF PESCR POF SEMANA (EM MEDTA)?

$\sqsupset 1 \sqsupset 2 \square=3 \quad 4 \quad \sqcup 5 \quad \square=6 \quad J$ todos os dise

12. QUANZAS HORAS FOR DIAZ horas
13.TEY A.TUDANTE DE PESCA?
n) n⿳⺈
U. sir. \]
L 2
\lrcorner 3 ou mais
E $E$ porente
(pazertesco: 7 arigo
7 empregado
14. $3 \AA \mathrm{C}$ REMUNERADOS?
] natc
$\square$ sir. QUAL O TIPO DE REMUNERACR̃O?

15. QUAI O CUSTO MENSAL COM A FEBCA?

16. QUAL A RECEITA MENSAL COH A PESCA 
17. QUATS AS ESFECIES QUE O SR. MAIS CAPTURA (EN ORDEM DE IMPORTANCIA)?

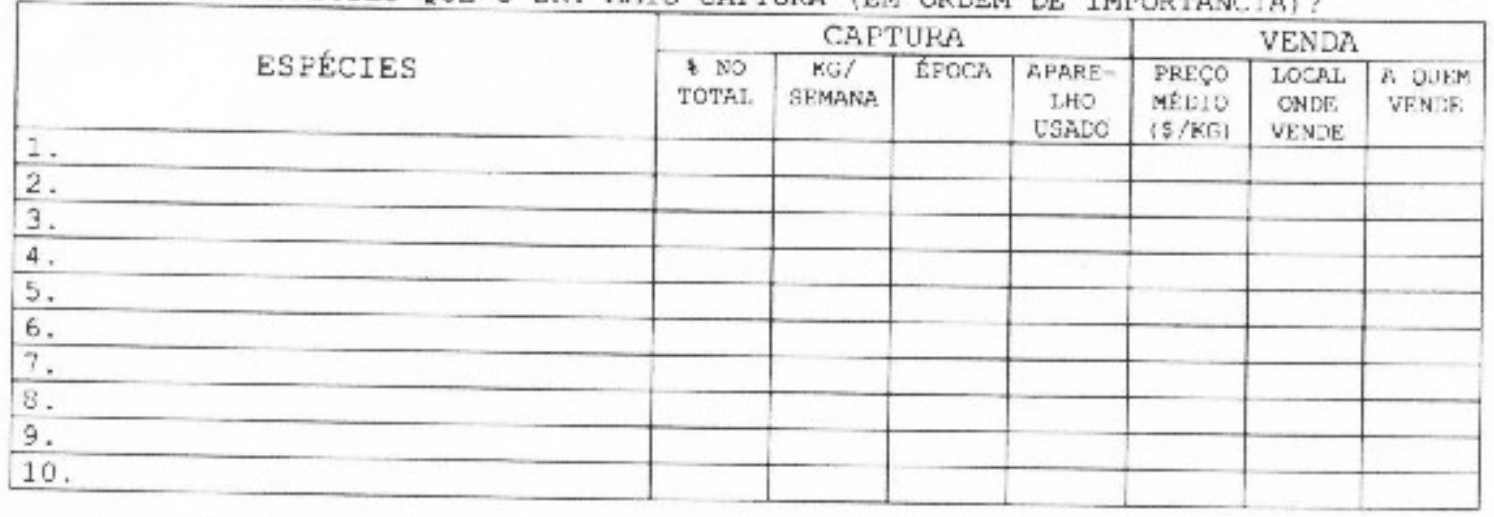

\begin{tabular}{|c|c|c|c|}
\hline B́POCA & APARELHO USADO & LOCAL CANDE VENDE & A QUEM VENDE \\
\hline 1. Boa & 1. TarraEa & 1. Barrance & 1. Peixeiro \\
\hline 2. Rusm & 2. Rede de espera & 2. Acanyamento & 2. Picado \\
\hline & Z.Espintel & 3. En casa & 3. Colonias de pesca \\
\hline & $\begin{array}{l}\text { 4. Vara/anzol } \\
\text { 5. Tinhada }\end{array}$ & 4. Peixaria & 4. outro \\
\hline & 6. Covo & 6. Bares & \\
\hline & 7. Outro & 3. Cutro & \\
\hline
\end{tabular}

\section{OBSERVAÇÕES}

1. PROBLEMAS QUE VEM ENFRENTANDO COM A ATIVIDADE PESQUEIRA:

2.SUGESTOES PARA A MELHORIA DA PESCR:

3. DECLARACÖES: 